\title{
Study on Design of Female Office Chair Based on Ergonomics
}

\author{
Xiaorong Dun, ${ }^{1}$ Yeying $\mathrm{Liu}^{2}$ \\ ${ }^{1}$ Industrial design, Hohai university, Changzhou, Jiangsu, 213000, China \\ ${ }^{2}$ Industrial design, Hohai university, Changzhou, Jiangsu, 213000, China
}

\begin{abstract}
In view of the fact that existing office chairs cannot fully meet the needs of office workers, especially the design of some adjustable parts, there is a lack of consideration for female size, body structure, and psychological needs. In this paper, through online and on-site research, combined with the results of the research, the existing office chairs are analyzed for related human-machine functions, and specific improvements for the chair surface, armrests, backrests, and footrests of female office chairs are proposed. Provide effective suggestions for improving the ergonomic design of female office chairs and determining design elements.
\end{abstract}

\section{Introduction}

The employment population in the tertiary industry has gradually increased, and the proportion of female white-collar workers has increased significantly. Women spend more time in the office sitting posture than men, and need more humane care in their designs. Therefore, the demand for female office chairs is more prominent, and the ergonomic requirements are more stringent. The most important function of the office chair is to support the human body, so that the human lumbar spine can maintain natural comfort even after long hours of work. Ergonomics emphasizes the mutual influence and interaction of people, things and the environment, and has an important guiding role in the design of female office chairs. Research on the ergonomic improvement of female office chairs under the working environment meets the dual functions of office and rest can effectively relieve fatigue, effectively improve work efficiency, unify comfort and design, and highlight the people-oriented design concept.

\section{Design elements of female office seats}

\subsection{Size factor}

\subsubsection{Seat height}

Seat height refers to the height from the ground to the position of the ischial support on the seat surface, that is, the height of the lower leg plus foot [1]. Sitting too high will cause the feet to hang, and the weight of the leg will press the blood vessels of the thigh, which will affect blood circulation; sitting too low will make the front edge of the thigh not reach the chair surface, and the body weight is concentrated on the nodes of the ischium, and Sitting too low will also cause the body to bend forward and increase the intensity of muscle activity in the back [2]. Refer to the standard design seat height range, in order to meet the needs of small-sized women, $370 \mathrm{~mm}$ to $450 \mathrm{~mm}$ is more reasonable.

\subsubsection{Seat width}

Seat width refers to the width of the horizontal plane when a person is seated. The seat width should meet the size required for the user to sit on the buttocks, and the seated person can freely adjust the sitting posture. According to the survey, the hip width index of women is generally larger than that of men, and the larger size of the hip width of women should be taken. In view of the increase in the range of office chair multi-function seats, the seat width is enlarged proportionally. The reasonable size of the seat width is $400-425 \mathrm{~mm}$.

\subsubsection{Seat depth}

Seat depth refers to the front-back distance of the seat surface. The seat depth should ensure that the knee socket is not compressed, and the waist and back can be well supported, and the user's hips should be fully supported. If the depth of the sitting surface is too deep, the pressure of the upper body of the human body will be concentrated on the upper part of the legs and the knees, and the time will cause numbness of the legs; if the sitting depth is too shallow, it will make people sit on the chair, so the depth of the seat should be followed: sitting depth is equal to the horizontal length of the upper half of the knee in the sitting position minus the $60 \mathrm{~mm}$ gap[3]. Considering the depth of office seats during leisure, the reasonable size of the seat depth is $400-430 \mathrm{~mm}$.

\footnotetext{
"Corresponding author's e-mail: 2113277795@qq.com
} 


\subsubsection{Foot rest}

The foot rest is the most important component that distinguishes the leisure seat from the office seat. It can provide good support for the user's calf extension when it is unfolded. However, in view of the special requirements for the structure and function of the footrest (opened footrests must be at least $390 \mathrm{~mm}$ away from the front of the seat surface to provide good support for the lower leg) [4].

\subsubsection{Armrests}

Work seats are generally not equipped with armrests. Seats with armrests must ensure the safety of the operator during work activities. Armrest height refers to the height of the upper surface of the armrest from the seat surface. The main role of the armrest is to support the arm to reduce the burden on the shoulder, and use the armrest to support the body when standing, sitting or changing posture. In order to prevent shrugs during use, the handrails should be designed according to users with small body, so the reasonable height of the handrails is $200-230 \mathrm{~mm}$. For liftable handrails, the minimum shall not be greater than $200 \mathrm{~mm}$ and the maximum shall not be less than $250 \mathrm{~mm}$.

\subsubsection{Back height}

Back height refers to the height of the highest point of the backrest from the seat surface. The height of the backrest is related to the shoulder height of the sitting position. For multi-functional seats, both office and leisure postures must be considered, so the height of the back must be based on the height of the leisure chair. The height of the back of the general leisure chair is between $520-700 \mathrm{~mm}$. The back width is the same as the seat width $400-425 \mathrm{~mm}$.

\begin{tabular}{|l|l|}
\hline Seat height & $400-510$ \\
\hline Seat depth & $400-420$ \\
\hline Seat width & $>400$ \\
\hline Back width & $\geq 360$ \\
\hline Back height & $\geq 360$ \\
\hline Armrest depth & $\geq 200$ \\
\hline Armrest width & $\geq 40$ \\
\hline Armrest height (from seat pad) & $\begin{array}{l}\text { Fixed armrest: } 200-250 \\
\text { Lifting armrest: Min } \leq 200 ; \\
\text { Max } \geq 250\end{array}$ \\
\hline
\end{tabular}

Figure 1. Office human ergonomics data

\begin{tabular}{|l|lllllll|}
\hline Peasurement items & 1 & 5 & 10 & 50 & 90 & 95 & 99 \\
\hline Seat height & & & & & & & \\
\hline Sitting shoulder height & & & & & & & \\
\hline Calf height & 789 & 809 & 819 & 855 & 891 & 901 & 920 \\
\hline Sit deep & 504 & 518 & 526 & 556 & 585 & 594 & 609 \\
\hline Hip width & 331 & 342 & 350 & 382 & 399 & 405 & 417 \\
\hline
\end{tabular}

Figure 2. Sitting body size (female)

Table 1. Dimensions of female office seats

\begin{tabular}{|l|l|l|}
\hline Design object & $\begin{array}{l}\text { Numerical } \\
\text { parameters }\end{array}$ \\
\hline Seat height & $370-450$ \\
\hline Seat width & $400-425$ \\
\hline Seat depth & $400-430$ \\
\hline Leg length & $>390$ & $200-230$ \\
\hline Brmrest height & $520-700$ \\
\hline Backrest height & $400-425$ \\
\hline
\end{tabular}




\subsection{Material analysis}

Women pay more attention to emotional needs than men. Studying the psychological feelings brought about by the commonly used materials and colors of office chairs can enable users to obtain a deeper emotional experience in addition to the instinctive level of experience including the function of the chair. Wooden seat products have a long service life and are not easily deformed, giving people a true, simple and natural psychological feeling; the leather material is breathable and comfortable, giving people a noble and gorgeous psychological feeling, suitable for women in middle and high-level management offices; plastic materials is hard to sit and easy to give people a cold psychological feeling; PU material is imitation made of leather material, with high comfort, giving people a delicate, soft and light psychological feeling, suitable for low-level office women; mesh cloth is breathable and elastic strong, it can reduce the restriction of feminine weight adjustment, giving people a delicate and elegant psychological feeling; stainless steel and other metal materials are well-made, strong and durable, and give people a thick, uniform modern sense.

In summary, the material scheme for female office seats is mainly leather and cloth, supplemented by materials such as metal and plastic. The integration of various materials should fully express the authenticity, simplicity, and subtle naturalness of each material, which can make the designed female office chair products have a sense of time and a natural atmosphere. The comprehensive use of materials and color matching form different textures, which can enrich people's visual and tactile sensations.

\subsection{Color analysis}

Feminine perception of color is stronger than male, which affects the mood and behavior of the office process, and even affects work efficiency. The improvement of the design of office chairs for women should not only follow the principles of harmony, economy, design innovation and environmental protection, but more importantly, combine the psychological and physiological characteristics of women to create colors suitable for female office chairs. [5]

The color selection of female office chairs should be concise, crisp and coordinated. Color with strong color contrast or high purity will attract people's attention and affect work efficiency, but it can also harmonize the monotonous working environment. For office women, you should choose a certain cohesive, deep color, you can use warm colors to match.

\section{Design improvement based on ergonomics}

\subsection{Improvement of chair surface and chair back}

The sitting habits of women and men are significantly different. Feminine white-collar workers will have some inappropriate sitting positions. If the chair design is not scientific and comfortable, it will cause varicose veins, even scoliosis and other physiological diseases. Improvement plan:1. The chair is bent downwards by a certain arc to reduce the compression of the muscles on one side of the leg; 2 . The backrest conforms to the curved structure of the female back, and the support points are designed to add the function of waist massage.

\subsection{Headrest improvement}

The problem with the headrest is that it is connected with the backrest as a whole. It cannot be rotated and adjusted up and down at any angle. It is easy to cause discomfort to the head when leaning back, especially when working women with pigtails. Improvement plan: 1 . Y The type bracket is reinforced, the force is uniform and the stability is strong. 2 . The headrest can be adjusted up and down and the rotation angle.

\subsection{Improved armrest}

Some armrests are connected to the chair surface, but not to the backrest, resulting in that the angle of the armrest cannot be adjusted according to the inclination angle of the backrest. Moreover, the width of the armrest is narrow, and can be adjusted up and down, but not left and right, which results in a small range of wrist movement when forming an arm support. Improvement plan: 1 . The armrest is connected with the backrest, the angle can be adjusted according to the inclination angle of the backrest; 2 . The shape of the armrest extends from near the back of the chair to a wide width, which can increase the range of movement of the arm when supporting. 3. Use the moving link mechanism as shown in the figure to realize the armrest can be adjusted left and right, front and rear.

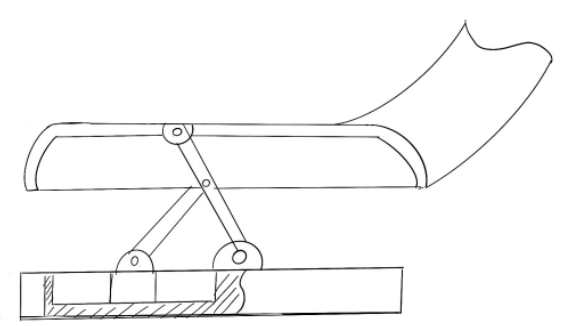

Figure 3. mobile link mechanism

\subsection{Improved footrest}

When the feet are not placed in a fixed position, women often appear in a cross-legged sitting position, and the 
pressure generated by the single measurement of the thigh will increase to nearly twice, so the design of the footrest of the female office chair should be considered to meet the needs of different sizes of human body. The tilt angle of the footrest should be adjustable. Improvement plan: 1. Add strong magnets at the connection between the bottom of the cushion and the footrest to prevent the footrest from vibrating up and down when moving the chair;

\subsection{Improved sensitivity of adjustable parts}

Feminine weight is lighter than male, and the seat height and backrest tilt angle adjustment resistance is large, which is inconvenient to achieve a wide range of adjustments, and the inflation pulse of the air pressure rod and the cylinder will cause violent tremor. Improvement plan: 1. Design an inductive lifting system, according to adjust the weight of the test taker; 2 . The built-in sensitive pressure sensor can sense the slight change of female body weight and pressure.

\section{Design plan}

The color uses wine red and black and white, simple and stylish. The chair surface material is leather and the reclining legs are aluminum alloy; the hinge is set at the connection between the armrest and the seat, and the plug-in method is used, and the headrest is provided with a buckle connection, can be rotated at any angle and adjusted up and down; the chair is bent downwards by a certain arc to reduce the compression of the unilateral leg muscles. The back of the chair is designed to move according to the curve of the female's back curve and the built-in sensitive pressure sensor can realize the adjustment of tiny precision; the armrest is connected to the backrest, and the angle of the backrest can be tilted; the backrest angle can be adjusted between 90 and 165 degrees; the connecting rod can be adjusted within the range of 30 degrees up and down, and is used to match the backrest tilt of any angle for users of different sizes. Refer to table 1 for related dimensions, shown in figure 4.
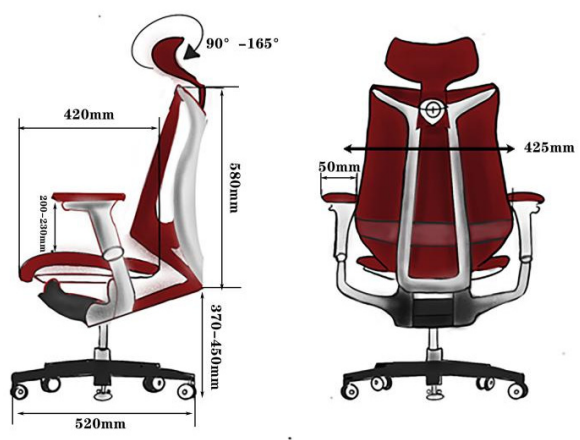

Figure 4. Design dimensions

\subsection{Mode conversion}

The sitting posture of people in office engineering cannot be maintained continuously, and the changes have certain regularity. If you stay in the same sitting posture for a long time, you will experience discomfort such as waist pain and fatigue. Therefore, the office chair needs to meet both office and leisure functions. On the basis of meeting the relevant size requirements determined in the previous stage, the final scheme (above Table 1) realizes the connection between the armrest and the backrest, which can be angled with the backrest; the backrest angle can vary from 85 degrees to 165 degrees. Achieve a tilt angle of 85 degrees to 105 degrees for the working mode; 105 degrees to 135 degrees for the leisure mode; 135 degrees to 165 degrees for the rest mode.

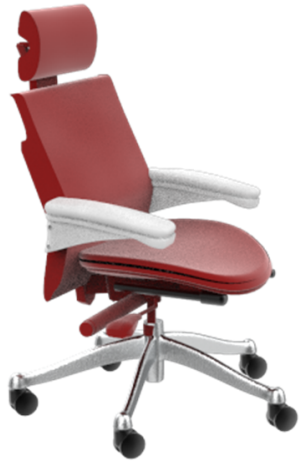

Figure 5. Office mode

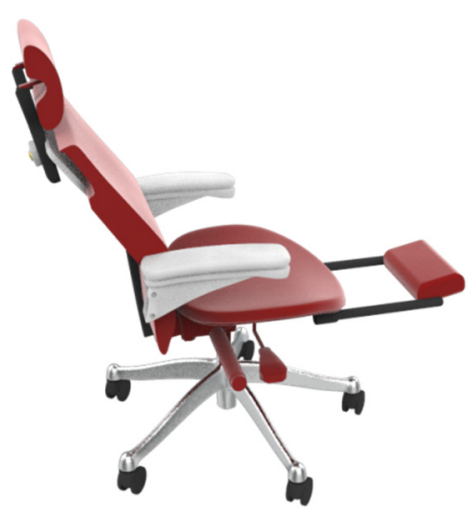

Figure 6. Leisure mode

\subsection{Detailed design}

Add storage box design for office seats, improve the monotony of office seat functions, and meet consumers' functional diversity needs. In addition, for the design of the footrest, the connecting rod can be adjusted within 30 degrees up and down. It is used to match the backrest of any female size and the backrest of any angle can be tilted. 


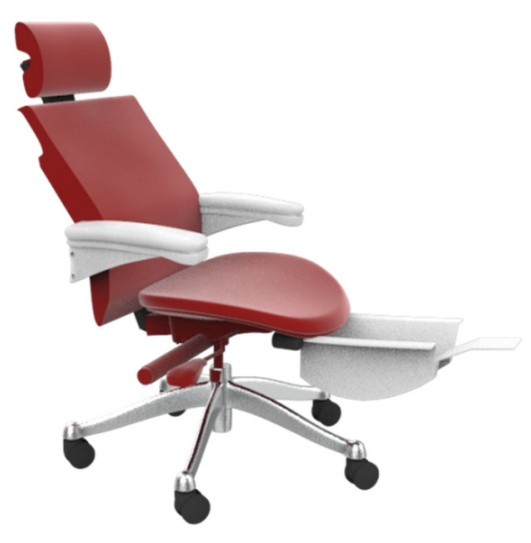

Figure 7. Storage box design

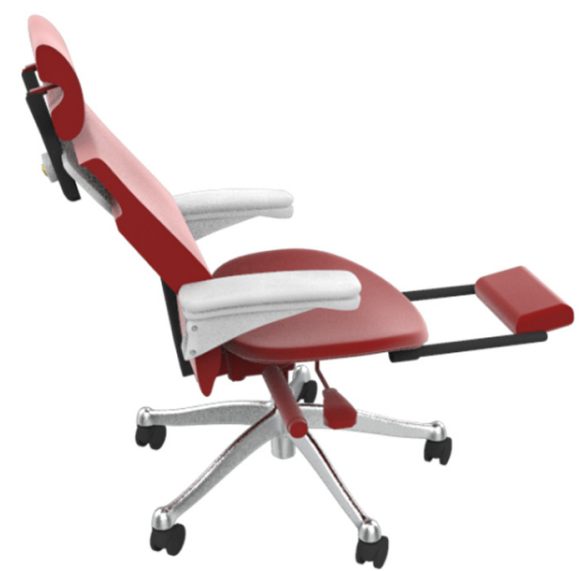

Figure 8. Foot support design

\section{Conclusion}

The office chair has both functions of office and leisure. It should meet the regular sitting posture and subconscious adjustment actions of female users in particular. It is structurally and functionally compatible with the sitting posture, providing sufficient compatibility to ensure various postures for women adjustable performance and comfort. The new office chair based on ergonomics maximizes the combination of theoretical knowledge such as ergonomics, material mechanics, and color psychology. Based on the physiological and psychological analysis of office women, the overall structure is mainly the head support mechanism and chair The back seat surface structure, armrest mechanism and footrest design, etc, allow users to get support from head to toe, greatly alleviating the fatigue caused by work, and improving feminine psychological satisfaction in the office process.

\section{References}

1. Li, D., Jiang, Y. (2014) Ergonomics. Electronic Industry Press, Beijing.

2. Shi, Y. (2011) Human Factors Engineering. Tsinghua University Press, Beijing.

3. Sun, M.L., Ha, J.N., Gao, H.B. (2019) Research on the scale design of seat furniture based on human dynamic factors. Aesthetic technology,7:184-208.

4. Cai, H. (2015) Design and research of multifunctional office lounge chair. Zhejiang University of Technology, Zhejiang.

5. Xia, F.Y. (2018) Research on Female Furniture Design Based on Ergonomics. human resource Management, 11:504. 